\title{
Perfil demográfico e epidemiológico dos usuários de medicamentos de alto custo no Sistema Único de Saúde
}

\author{
Francisco de Assis Acurcio** \\ Cristina Mariano Ruas Brandão*** \\ Augusto Afonso Guerra Júnior**** \\ Mariângela Leal Cherchiglia*****

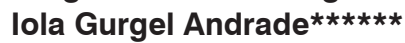

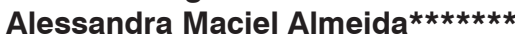 \\ Grazielle Dias da Silva $* * * * * * * *$ \\ Odilon Vanni de Queiroz $* * * \star * * * * *$ \\ Daniel Resende Faleiros $* * \star \star \star \star \star \star * * *$
}

\begin{abstract}
O Programa de Medicamentos Excepcionais, do Ministério da Saúde, provê, ao tratamento de doenças, medicamentos de alto valor unitário, ou que, em caso de uso crônico ou prolongado, configurem um tratamento de custo elevado. Com o objetivo de descrever o perfil demográfico e epidemiológico dos pacientes atendidos pelo programa, realizou-se um relacionamento probabilístico-determinístico de dados provenientes de registros do Datasus: Autorizações de Procedimentos de Alta Complexidade/Alto Custo (Apac/SIA) e Sistema de Informação sobre Mortalidade (SIM). A coorte formada pelo pareamento das bases de dados identificou 611.419 indivíduos que iniciaram o tratamento no período de 2000-2004. As análises foram desagregadas por sexo, região de residência, diagnósticos e medicamentos mais utilizados. A construção desta coorte histórica propiciou a descrição das características demográficas, epidemiológicas e de utilização de medicamentos dos usuários do programa. Além disso, o banco de dados gerado viabiliza uma série de análises específicas por doenças, que podem contribuir para avaliações de efetividade e eficiência de alternativas terapêuticas constantes nos protocolos clínicos, com o objetivo de fornecer subsídios aos tomadores de decisão no que tange ao planejamento das ações e oferta de medicamentos de alto custo pelo SUS.
\end{abstract}

Palavras-chave: Utilização de medicamentos. Alto custo. Pareamento. SUS.

\footnotetext{
* Este artigo apresenta resultados do projeto de pesquisa "Avaliação Farmacoeconômica e Epidemiológica do Programa de Medicamentos Excepcionais do SUS-Brasil". Foi realizado com o apoio financeiro do Conselho Nacional de Desenvolvimento Científico e Tecnológico (CNPq), da Fundação de Amparo à Pesquisa do Estado de Minas Gerais (Fapemig) e parceria da SES/MG e Ministério da Saúde.

os autores agradecem os integrantes dos Grupos de Pesquisa em Farmacoepidemiologia e em Economia da Saúde da UFMG por sua contribuição no desenvolvimento da pesquisa.

** Médico, professor do Departamento de Farmácia Social da Faculdade de Farmácia da Universidade Federal de Minas Gerais (UFMG), pós-doutor em Farmacoeconomia

*** Farmacêutica, doutoranda no Programa de Pós-Graduação em Saúde Pública da Faculdade de Medicina da UFMG. **** Farmacêutico, superintendente da Assistência Farmacêutica da Secretaria de Estado da Saúde de Minas Gerais (SES/ MG), doutorando no Programa de Pós-Graduação em Saúde Pública da Faculdade de Medicina da UFMG.

$\star \star \star \star \star$ Médica, professora do Departamento de Medicina Preventiva e Social da Faculdade de Medicina da UFMG, doutora em Saúde Pública.

$\star \star \star \star \star \star$ Economista, professora do Departamento de Medicina Preventiva e Social da Faculdade de Medicina da UFMG, doutora em Demografia.

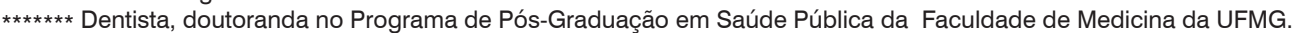
******** Farmacêutica, assessora da Superintendência da Assistência Farmacêutica da SES/MG, mestre em Saúde Pública. ********* Médico, especialista em regulação da Agência Nacional de Saúde Suplementar, mestre em Saúde Pública. $* \star * * * \star * * *$ Advogado, assessor da Superintendência da Assistência Farmacêutica da SES/MG.
} 


\section{Introdução}

A Constituição Federal de 1988 estabelece o direito à saúde, orientado pelos princípios da universalidade, igualdade e equidade, mediante a garantia ao cidadão do acesso às ações e serviços para promoção, proteção e recuperação da saúde.

Com intuito de viabilizar tal direito, o Sistema Único de Saúde (SUS) foi disciplinado pelo art. 198 e seguintes e regulamentado por leis que dispõem sobre as condições para promoção, proteção e recuperação da saúde, a par da organização e do funcionamento dos serviços correspondentes e que disciplinam a participação da comunidade na gestão do sistema e as transferências intergovernamentais de recursos financeiros na área da saúde.

Assim, cada cidadão brasileiro tem garantido o acesso às ações e aos serviços do SUS, incluída aí a assistência terapêutica e farmacêutica integral (BRASIL, 1990).

Entretanto, são muitos os desafios a serem enfrentados por gestores e profissionais do SUS para viabilizar o acesso à assistência farmacêutica. Apesar das dificuldades enfrentadas, avanços relevantes têm sido obtidos neste campo, a exemplo de programas como o de Medicamentos de Dispensação Excepcional/Alto Custo, destinados ao tratamento de doenças tanto raras quanto de alta prevalência, desde que com indicação de uso de medicamento de alto valor unitário, ou que, em caso de uso crônico ou prolongado, seja um tratamento de custo elevado.

Os usuários destes medicamentos são pacientes transplantados, portadores de insuficiência renal crônica, osteoporose, esclerose múltipla, hepatite viral crônica B e C, epilepsia, esquizofrenia refratárias, doenças genéticas como a fibrose cística, doença de Gaucher, entre outras (BRASIL, 2006).

$A$ aquisição destes medicamentos é programada pelas Secretarias de Estado de Saúde (SES), por meio da Autorização de Procedimentos de Alta Complexidade/ Custo (Apac), instrumento do Sistema de Informações Ambulatoriais (SIA/SUS) para a coleta de informações gerenciais e cobrança de procedimentos de alta complexidade, assim como o cadastramento do usuário no banco de dados nacional (BRASIL, 2007a).

O controle dos pacientes é individualizado, com identificação por meio de Cadastro de Pessoa Física (CPF), diagnóstico feito com base na Classificação Internacional de Doenças (CID) e determinação de quantidades máximas de medicamentos, com critérios estabelecidos para dispensação, como exames e testes diagnósticos.

As portarias publicadas pelo Ministério da Saúde (MS) servem como referencial para a seleção dos medicamentos que são disponibilizados nos Estados, que podem optar por fornecer apenas um entre os medicamentos indicados como equivalentes entre si, bem como, para um mesmo fármaco, somente uma das apresentações farmacêuticas.

De acordo com a Norma Operacional de Assistência à Saúde 01/2002, cabe ao Ministério da Saúde o financiamento das ações de alta complexidade/alto custo e a garantia de acesso aos procedimentos de alta complexidade é de responsabilidade solidária entre o MS e as Secretarias de Estados de Saúde e do Distrito Federal. Segundo essa mesma norma, o gestor estadual (secretário de Saúde) é responsável pela gestão da política de alta complexidade/alto custo no âmbito do Estado, mantendo vinculação com a política nacional, sendo consideradas intransferíveis as funções de definição de prioridades assistenciais e programação da alta complexidade (BRASIL, 2002).

Os recursos financeiros disponibilizados pelo MS para o financiamento desse Programa de Saúde estão consignados no Fundo de Ações Estratégicas e Compensação (Faec) e são repassados mensalmente aos Estados e ao Distrito Federal, com base na média trimestral da informação de cada Unidade da Federação apresentada por meio da Apac. O cofinanciamento por parte do Estado se dá entre a diferença do valor do medicamento na tabela de procedimentos financiado pela União - e o valor efetivamente pago pelo gestor estadual na aquisição do medicamento. O Ministério da Saúde realiza, ainda, a aquisição centralizada e a distribuição direta aos Estados de 11 dos 231 medicamentos padronizados, participando com 
$100 \%$ do financiamento desses produtos, a saber: a imiglucerase $200 \mathrm{UI}$, imunoglobulina humana $5 \mathrm{~g}$, alfapeginterferona $2 \mathrm{a}(180 \mathrm{mcg})$ e $2 b$ ( $80 \mathrm{mcg}, 100 \mathrm{mcg}$ e $120 \mathrm{mcg}$ ), alfainterferona $2 \mathrm{~b}(3 \mathrm{MUI}, 5 \mathrm{MUI}$ e $10 \mathrm{MUI})$ e alfaepoetina humana 2000 Ul e 4000 Ul.

Sabe-se que o número de pacientes cadastrados no Programa de Medicamentos de Dispensação Excepcional vem crescendo substancialmente, todavia, como a informação sobre a dispensação de medicamentos pelo programa é focada no procedimento, não se sabe ao certo o total de indivíduos que são atendidos anualmente e não se conhece o perfil destes pacientes. Além disso, os gastos com estes medicamentos têm apresentado crescimento contínuo: em 2003, foram gastos aproximadamente $\mathrm{R} \$ 1,05$ bilhão com a aquisição desses medicamentos; em 2005, estes recursos já somavam R \$1,92 bilhão (BRASIL, 2007a).

Tendo em vista os crescentes aportes financeiros destinados ao programa e considerando a escassez de estudos nacionais sobre a utilização de medicamentos de alto custo, torna-se oportuna a realização de investigações que avaliem esse programa e possam contribuir para uma melhor compreensão do perfil dos seus usuários, do uso de medicamentos e dos gastos a ele relacionados. O conhecimento do padrão de utilização de serviços e ações de saúde tem sido enfatizado, por ser considerado essencial para que as respostas às demandas por esses serviços reflitam decisões equânimes e efetivas em relação aos custos. Isto porque tal padrão de utilização oferece insumos durante o processo de alocação e geração de recursos (SAWYER et al., 2002).

O presente estudo procura descrever o perfil demográfico, epidemiológico e de utilização de medicamentos dos indivíduos atendidos pelo Programa de Medicamentos de Dispensação Excepcional do Ministério da Saúde, Brasil, no período de 2000 a 2004.

\section{Métodos}

\section{Desenho e população do estudo}

Coorte histórica formada por pacientes cobertos pelo Programa de Medicamentos de Dispensação Excepcional, que iniciaram tratamento no período de 2000 a 2004 e apresentaram, no mínimo, dois registros de procedimentos no primeiro semestre de acompanhamento.

\section{Fonte de dados}

Uma Base Nacional de Usuários de Medicamentos de Dispensação Excepcional foi formada a partir dos registros existentes no banco de dados do subsistema de Procedimentos de Alta Complexidade (Apac) do SIA/SUS, utilizando-se o método de linkage determinístico-probabilístico. Para isto, foram selecionados especificamente os procedimentos de relevância para o estudo, que, neste caso, recebem o código "36". O linkage teve como objetivo encontrar todos os registros referentes a um mesmo indivíduo nos arquivos e unificá-los em um único registro, de forma a habilitar o seguimento farmacoterapêutico dos pacientes em uso de medicamentos de dispensação excepcional no SUS, no período analisado. Os procedimentos metodológicos adotados para a realização do linkage foram os mesmos aplicados na construção da Base Nacional em Terapia Renal Substitutiva (CHERCHIGLIA et al., 2007).

Como a informação sobre a ocorrência de óbito registrada no subsistema Apac está subestimada, realizou-se um linkage dos registros da Base Nacional de Usuários de Medicamentos de Dispensação Excepcional com aqueles do Sistema de Informação de Mortalidade (SIM). O objetivo deste relacionamento foi comparar e complementar as informações de mortalidade dessa base de dados com as informações oriundas do SIM, também adotando procedimentos semelhantes aos aplicados na Base Nacional em Terapia Renal Substitutiva (QUEIROZ et al., 2009).

\section{Variáveis}

Foram consideradas as seguintes categorias de variáveis:

- demográficas - sexo, idade, região de residência no início do tratamento e ano de início de trata- 
mento (definido pela data em que o indivíduo recebeu a primeira medicação no Programa);

- clínicas - diagnóstico no início do tratamento segundo a CID-10, tempo de tratamento (número de meses com registro de procedimentos com código "36" na Apac), óbitos e a causa da morte de acordo com a CID-10;

- medicamentos de dispensação excepcional - tipo de medicamento utilizado no início do tratamento descrito pelo nome do seu princípio ativo.

\section{Análise dos dados}

A análise descritiva dos dados incluiu distribuições de frequências para as variáveis categóricas, além de medidas de tendência central (média, mediana) para as variáveis contínuas. O teste do qui-quadrado foi utilizado para avaliar diferenças de proporções. O nível de significância adotado foi $5 \%$.

Adicionalmente, foram calculadas as taxas de pacientes atendidos pelo Programa, estratificadas por sexo, considerando-se o número de pacientes incluídos no estudo, por 100 habitantes, na população residente nas cinco regiões brasileiras, no período de 2000 a 2004. Essas taxas também foram calculadas segundo a faixa etária do paciente.

Os principais diagnósticos dos indivíduos no início do tratamento foram selecionados e agrupados segundo capítulos da CID-10 e descreveram-se as causas de morte mais frequentes. A análise estatística dos dados foi realizada com o auxílio do software SPSS ${ }^{\circledR} 16$.

O estudo foi submetido e aprovado pela Comissão de Ética em Pesquisa da UFMG (Parecer no ETIC 0101/06).

\section{Resultados}

\section{Características demográficas}

Foram excluídos 159.661 indivíduos por não cumprirem os critérios de inclusão predefinidos. A coorte foi composta por 611.419 usuários. A maioria dos participantes era do sexo feminino $(63,54 \%)$ e com idade entre 30 e 69 anos (61,96\%), apresentando idade média de 46,5 $\pm 20,9$ anos e mediana de 48 anos. Entre os homens, observou-se maior proporção na faixa etária de 30 a 59 anos, enquanto para as mulheres as maiores proporções ocorreram no grupo de 40 a 69 anos. Diferenças estatisticamente significativas entre sexos foram observadas nas faixas etárias de 5 a 9 e de 50 anos ou mais, com maiores proporções de mulheres, e nas de 0 a 4 e 10 a 49 anos, em que predominam os homens (Tabela 1).

A distribuição segundo região de residência mostra que a maioria dos pacientes residia no Sudeste e Nordeste $(71,53 \%)$ no início do tratamento. Comparando-se os sexos, verificou-se maior participação de homens residentes no Sudeste e Sul, enquanto as mulheres apresentaram maiores proporções no Nordeste, Centro-Oeste e Norte $(p<0,01)$ (Tabela 1).

Dos 611.419 indivíduos, $24,54 \%$ (IC 95\% 24,43-24,64) apresentavam 2000 como o ano do primeiro registro de Apac referente a medicamentos de dispensação excepcional. Para 12,39\% (IC 95\% 12,31-12,47), esse registro se deu em 2001 com tendência crescente até 2004: 16,51\% (IC 95\% 16,42-16,60) em 2002; 22,92\% (IC 95\% 22,82-23,03) em 2003; e 23,64\% (IC 95\% 23,53-23,74) em 2004. A estratificação por sexo demonstrou a mesma tendência de utilização no decorrer do período, com predomínio das mulheres em relação aos homens, sendo as diferenças estatisticamente significativas $(p<0,001)$ (Gráfico 1). Vale ressaltar que $7,80 \%$ dos indivíduos com o primeiro registro de Apac em 2000 relataram data de início de tratamento anterior àquele ano. Assim, 138.231 usuários entraram efetivamente no programa em 2000 ou não relataram início de tratamento antes desta data.

As taxas de pacientes atendidos pelo Programa de Medicamentos de Dispensação Excepcional (por 100 habitantes) na população brasileira, estratificadas por sexo e ano de registro da primeira Apac, segundo faixa etária e região de residência, são apresentadas na Tabela 2. Considerando-se o ano de registro no Programa, as maiores taxas, para ambos os sexos, foram observa- 
TABELA 1

Distribuição dos usuários do Programa de Medicamentos de Dispensação Excepcional por sexo, segundo faixa etária e região de residência Brasil - 2000-2004

\begin{tabular}{|c|c|c|c|c|c|c|c|}
\hline \multirow{2}{*}{$\begin{array}{l}\text { Faixa etária e região } \\
\text { de residência }\end{array}$} & \multicolumn{2}{|c|}{ Mulheres } & \multicolumn{2}{|c|}{ Homens } & \multirow{2}{*}{ Valor $p$} & \multicolumn{2}{|c|}{ Total } \\
\hline & $\%$ & IC $95 \%$ & $\%$ & IC $95 \%$ & & $\%$ & IC $95 \%$ \\
\hline Faixa etária (em anos) & 100,00 & - & 100,00 & - & - & 100,00 & - \\
\hline 0 a 4 & 1,31 & $1,27-1,35$ & 2,11 & $2,05-2,17$ & $<0,001$ & 1,60 & $1,57-1,63$ \\
\hline 5 a 9 & 3,49 & $3,43-3,55$ & 2,92 & $2,85-3,00$ & $<0,001$ & 3,28 & $3,24-3,33$ \\
\hline 10 a 14 & 2,90 & $2,85-2,95$ & 4,06 & $3,98-4,14$ & $<0,001$ & 3,32 & $3,28-3,37$ \\
\hline 15 a 19 & 2,66 & $2,61-2,71$ & 6,59 & $6,49-6,69$ & $<0,001$ & 4,09 & $4,05-4,14$ \\
\hline 20 a 29 & 9,61 & $9,52-9,70$ & 12,53 & $12,39-12,67$ & $<0,001$ & 10,67 & $10,60-10,75$ \\
\hline 30 a 39 & 14,01 & $13,90-14,12$ & 14,27 & $14-12-14,41$ & 0,006 & 14,10 & $14,02-14,19$ \\
\hline 40 a 49 & 14,97 & $14,86-15,09$ & 19,15 & $18,98-19,31$ & $<0,001$ & 16,49 & $16,40-16,59$ \\
\hline 50 a 59 & 16,05 & $15,94-16,17$ & 15,27 & $15,12-15,42$ & $<0,001$ & 15,77 & $15,68-15,86$ \\
\hline 60 a 69 & 17,84 & $17,72-17,96$ & 11,69 & $11,55-11,82$ & $<0,001$ & 15,60 & $15,51-15,69$ \\
\hline 70 a 79 & 12,66 & $12,56-12,77$ & 8,16 & $8,05-8,28$ & $<0,001$ & 11,02 & $10-94-11,10$ \\
\hline 80 e mais & 4,41 & $4,34-4,47$ & 3,17 & $3,10-3,24$ & $<0,001$ & 3,95 & $3,90-4,00$ \\
\hline Sem registro & 0,09 & $0,08-0,10$ & 0,09 & $0,08-0,11$ & 0,683 & 0,09 & $0,08-0,10$ \\
\hline Região de residência & 100,00 & - & 100,00 & - & - & 100,00 & - \\
\hline Sudeste & 38,79 & $38,63-38,94$ & 47,26 & $47,05-47,47$ & $<0,001$ & 41,88 & $41,75-42,00$ \\
\hline Nordeste & 32,48 & $32,33-32,63$ & 24,74 & $24,56-24,92$ & $<0,001$ & 29,66 & $29,54-29,77$ \\
\hline Sul & 10,51 & $10,41-10,61$ & 11,89 & $11,76-12,02$ & $<0,001$ & 11,01 & $10,93-11,09$ \\
\hline Centro-Oeste & 7,60 & $7,52-7,69$ & 7,18 & $7,07-7,28$ & $<0,001$ & 7,45 & $7,38-7,51$ \\
\hline Norte & 10,62 & $10,53-10,72$ & 8,93 & $8,82-9,05$ & $<0,001$ & 10,01 & $9,93-10,08$ \\
\hline Total (n. absolutos) & 388.471 & - & 222.948 & - & - & 611.419 & - \\
\hline
\end{tabular}

Fonte: Base Nacional de Usuários de Medicamentos de Dispensação Excepcional no SUS (UFMG).

GRÁFICO 1

Pacientes, por sexo, segundo ano do primeiro registro no Programa de Medicamentos de Dispensação Excepcional

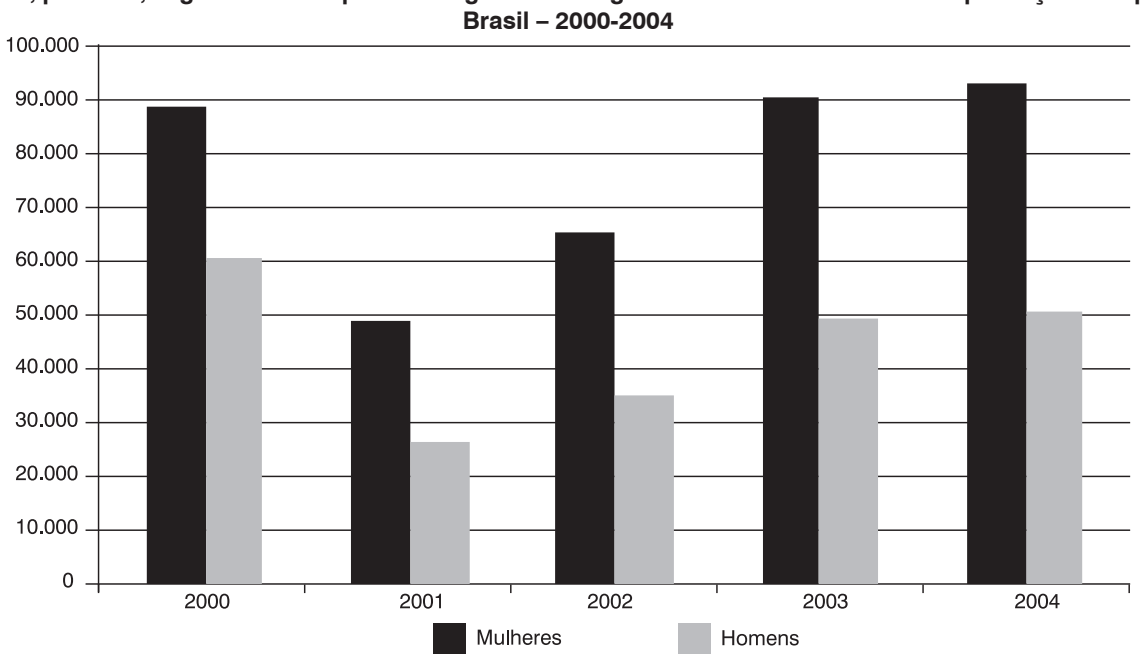

Fonte: Base Nacional de Usuários de Medicamentos de Dispensação Excepcional no SUS (UFMG). 
das em 2000 e as menores em 2001, com tendência crescente nos anos subsequentes. De modo geral, as taxas de pacientes atendidos pelo programa elevaram-se de acordo com o aumento da idade, com exceção da faixa etária de 80 anos ou mais. Estratificando-se pelo sexo, as mulheres apresentaram maiores taxas do que os homens em todas as faixas etárias, com exceção na de 15 a 19 anos. Quanto à região de residência, entre 2000 e 2002, as maiores taxas de pacientes atendidos foram observadas no Norte e as menores, no Sul. Já em 2003 e 2004, as maiores taxas se encontravam entre os residentes na Região Sudeste (Tabela 2).

\section{Características clínicas}

De acordo com as categorias estabelecidas pela CID-10, os diagnósticos mais prevalentes no início do tratamento entre os usuários do programa estão agrupados no capítulo das doenças do aparelho geniturinário $(22,10 \%)$, seguido das doenças do sistema osteomuscular e do tecido conjuntivo $(21,69 \%)$ e das doenças endócrinas, nutricionais e metabólicas $(13,87 \%)$. Estes três capítulos englobam $55,66 \%$ de todos os diagnósticos. Diferenças significativas foram observadas entre os sexos, com maiores proporções, para as mulheres, de neoplasias $(1,46 \%$, contra $0,77 \%$ para os homens), doenças endócrinas, nutricionais e metabólicas $(15,27 \%$ vs. $11,42 \%)$ e doenças do sistema osteomuscular $(31,92 \%$ vs. $3,86 \%)(p<0,01)$. Já entre os homens, verificou-se maior participação nas doenças infecciosas e parasitárias $(8,96 \%$ contra $2,93 \%$ para as mulheres), doenças do sangue $(1,57 \%$ vs. $1,04 \%)$, transtornos mentais e comportamentais $(15,47 \%$ vs. $6,78 \%)$, doenças do aparelho digestivo (3,28\% vs. $2,68 \%)$, doenças da pele ( $8,29 \%$ vs. $3,26 \%)$, doenças do aparelho geniturinário $(24,84 \%$ vs. $20,53 \%$ ) e fatores que influenciam o estado de saúde e o contato com serviços $(4,32 \%$ vs. $1,97 \%)(p<0,01)$ (Tabela 3$)$.

Das 1.277 doenças relatadas, 15 $(1,17 \%)$ representaram os diagnósticos (CID-10) mais frequentes, englobando $54,89 \%$ dos usuários do programa. As maiores prevalências foram para doença renal em estádio final $(9,22 \%)$, seguida de esquizofrenia paranoide $(6,52 \%)$ e osteoporose pós-menopáusica com fratura patológica $(6,19 \%)$. Entre as mulheres, as maiores proporções de diagnósticos referem-se a hipercolesterolemia pura $(4,42 \%$, contra $4,21 \%$ para os homens), osteoporose em outras doenças classificadas em outra parte $(4,45 \%$ vs. $0,32 \%)$ e outras hiperfunções da hipófise $(3,97 \%$ vs. $0,95 \%)(p<0,001)$. Para os homens, os valores mais elevados correspondem a doença renal em estádio final $(13,75 \%$, contra $6,63 \%$ para as mulheres), esquizofrenia paranoide $(10,22 \%$ vs. $4,40 \%)$, hepatite viral crônica C $(7,37 \%$ vs 2,38\%), insuficiência renal crônica não especificada $(6,06 \%$ vs. $2,87 \%)$, rim transplantado $(3,16 \%$ vs. $1,55 \%)$, acne vulgar (3,37\% vs. $1,29 \%)$, doença de Parkinson $(2,77 \%$ vs. $1,44 \%)$ e hipopituitarismo $(2,49 \%$ vs. $1,06 \%)(p<0,001)$. Erros de digitação ou outros problemas ocorreram no registro de osteoporose pós-menopáusica com e sem fraturas patológicas e em endometriose uterina, nas quais existem alguns registros de ocorrência em indivíduos do sexo masculino (Tabela 4).

Apenas 15 dos 102 diferentes tipos de medicamentos registrados $(14,71 \%)$ foram utilizados por 408.151 usuários $(66,75 \%)$ no início do tratamento. Os medicamentos mais utilizados foram eritropoetina humana recombinante, alendronato e calcitriol. As mulheres apresentaram maior utilização dos fármacos: alendronato $(16,45 \%$, contra $1,21 \%$ para os homens), calcitonina sintética de salmão $(7,02 \%$ vs. $0,62 \%)$, goserelina $(5,35 \%$ vs. $0,10 \%)$, azatioprina $(3,47 \%$ vs. $2,38 \%)$, goserelina + triptorelina + leuprolide $(4,26 \%$ vs. $0,52 \%)$ e sinvastatina $(1,93 \%$ vs. $1,82 \%)(p<0,01)$. Os fármacos mais utilizados pelos homens foram: eritropoetina humana recombinante $(18,0 \%$, contra $8,32 \%$ para as mulheres), calcitriol $(6,84 \%$ vs. $6,45 \%)$, olanzapina $(6,83 \%$ vs. $3,04 \%)$, risperidona (6,56\% vs. $2,85 \%)$, ciclosporina (4,79\% vs. $2,03 \%)$, interferon alfa $2 \mathrm{a}$ ou $2 \mathrm{~b}$ $(5,12 \%$ vs. $1,57 \%)$, isotretinoína $(4,71 \%$ vs. $1,74 \%)$ e acitretina (3,38\% vs. $1,34 \%)$ $(p<0,001)$ (Tabela 5). 


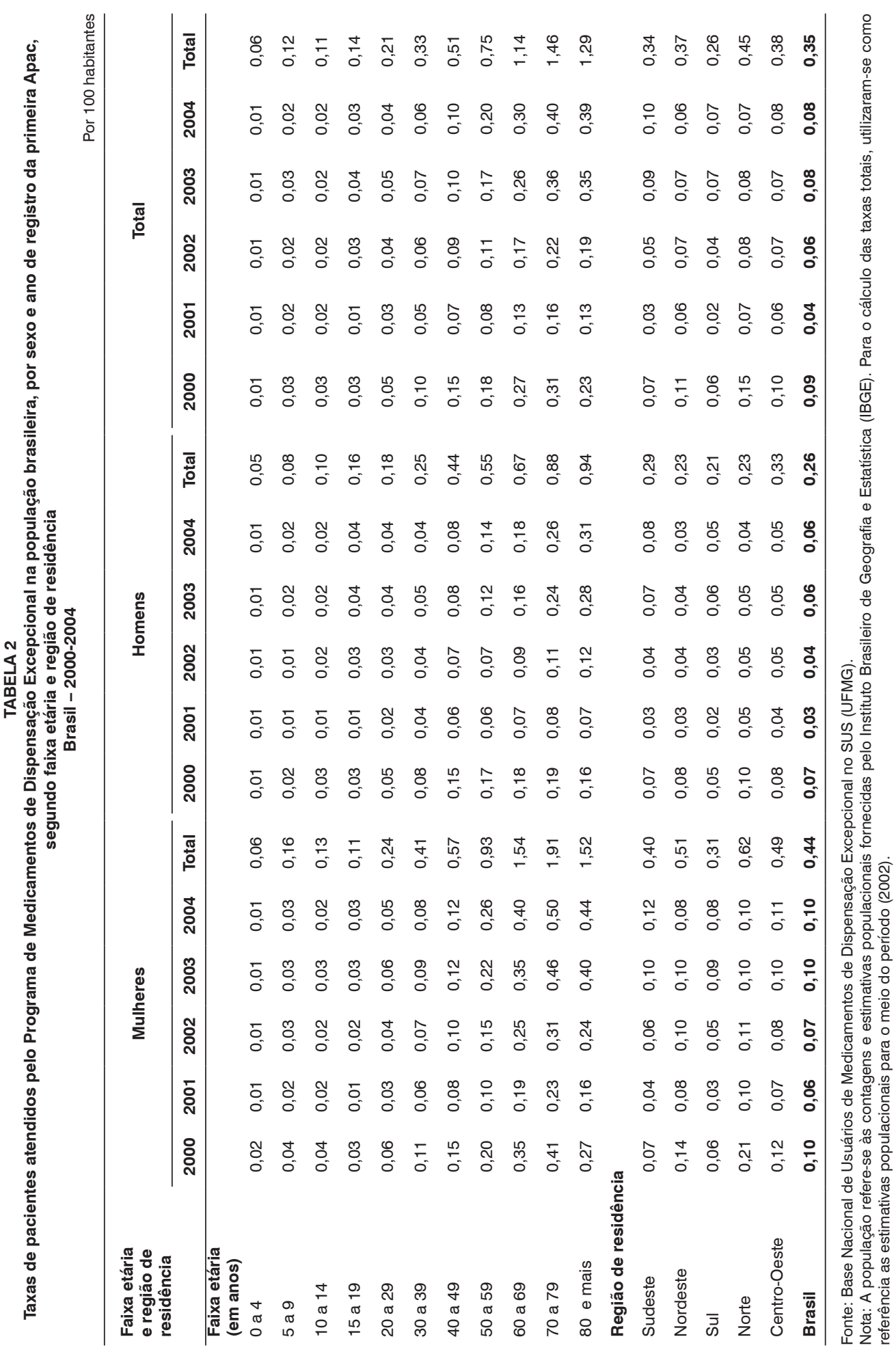


TABELA 3

Distribuição dos usuários do Programa de Medicamentos de Dispensação Excepcional, por sexo, segundo os capítulos da CID-10 referentes aos diagnósticos registrados no início do tratamento Brasil - 2000-2004

\begin{tabular}{|c|c|c|c|c|c|c|c|c|}
\hline & \multirow{2}{*}{ Capítulos da CID-10 } & \multicolumn{2}{|c|}{ Mulheres } & \multicolumn{2}{|c|}{ Homens } & \multirow{2}{*}{ Valor $p$} & \multicolumn{2}{|c|}{ Total } \\
\hline & & $\%$ & IC $95 \%$ & $\%$ & IC $95 \%$ & & $\%$ & IC $95 \%$ \\
\hline 1 & $\begin{array}{l}\text { Algumas doenças infeccio- } \\
\text { sas e parasitárias }\end{array}$ & 2,93 & $2,88-2,98$ & 8,96 & $8,84-9,07$ & $<0,001$ & 5,13 & $5,07-5,18$ \\
\hline 2 & Neoplasias & 1,46 & $1,42-1,50$ & 0,77 & $0,73-0,81$ & $<0,001$ & 1,21 & $1,18-1,23$ \\
\hline 3 & $\begin{array}{l}\text { Doenças do sangue e dos } \\
\text { órgãos hematopoiéticos e } \\
\text { alguns transtornos imuni- } \\
\text { tários }\end{array}$ & 1,04 & $1,00-1,07$ & 1,57 & $1,52-1,62$ & $<0,001$ & 1,23 & $1,20-1,26$ \\
\hline 4 & $\begin{array}{l}\text { Doenças endócrinas, } \\
\text { nutricionais e metabólicas }\end{array}$ & 15,27 & $15,16-15,39$ & 11,42 & $11,28-11,55$ & $<0,001$ & 13,87 & $13,78-13,95$ \\
\hline 5 & $\begin{array}{l}\text { Transtornos mentais e com- } \\
\text { portamentais }\end{array}$ & 6,78 & $6,70-6,86$ & 15,47 & $15,32-15,62$ & $<0,001$ & 9,95 & $9,88-10,03$ \\
\hline 6 & Doenças do sistema nervoso & 7,96 & $7,87-8,04$ & 10,91 & $10,78-11,04$ & $<0,001$ & 9,04 & $8,96-9,11$ \\
\hline 7 & Doenças do olho e anexos & 0,06 & $0,05-0,06$ & 0,07 & $0,06-0,08$ & 0,028 & 0,06 & $0,05-0,07$ \\
\hline 9 & $\begin{array}{l}\text { Doenças do aparelho } \\
\text { circulatório }\end{array}$ & 1,32 & $1,29-1,36$ & 3,14 & $3,07-3,21$ & $<0,001$ & 1,99 & $1,95-2,02$ \\
\hline 10 & $\begin{array}{l}\text { Doenças do aparelho } \\
\text { respiratório }\end{array}$ & 2,28 & $2,23-2,33$ & 2,51 & $2,45-2,58$ & $<0,001$ & 2,36 & $2,33-2,40$ \\
\hline 11 & $\begin{array}{l}\text { Doenças do aparelho } \\
\text { digestivo }\end{array}$ & 2,68 & $2,63-2,73$ & 3,28 & $3,21-3,36$ & $<0,001$ & 2,90 & $2,86-2,94$ \\
\hline 12 & $\begin{array}{l}\text { Doenças da pele e do tecido } \\
\text { subcutâneo }\end{array}$ & 3,26 & $3,21-3,32$ & 8,29 & $8,17-8,40$ & $<0,001$ & 5,10 & $5,04-5,15$ \\
\hline 13 & $\begin{array}{l}\text { Doenças do sistema } \\
\text { osteomuscular e do tecido } \\
\text { conjuntivo }\end{array}$ & 31,92 & $31,78-32,07$ & 3,86 & $3,78-3,94$ & $<0,001$ & 21,69 & $21,59-21,79$ \\
\hline 14 & $\begin{array}{l}\text { Doenças do aparelho } \\
\text { geniturinário }\end{array}$ & 20,53 & $20,41-20,66$ & 24,84 & $24,66-25,02$ & $<0,001$ & 22,10 & $22,00-22,21$ \\
\hline 15 & Gravidez, parto e puerpério & 0,01 & $<0,01-0,01$ & 0,00 & - & $<0,001$ & 0,01 & $<0,01-0,01$ \\
\hline 16 & $\begin{array}{l}\text { Algumas afecções origina- } \\
\text { das no período perinatal }\end{array}$ & $<0,01$ & - & $<0,01$ & - & 0,574 & $<0,01$ & - \\
\hline 17 & $\begin{array}{l}\text { Malformações congênitas, } \\
\text { deformidades e anomalias } \\
\text { cromossômicas }\end{array}$ & 0,42 & $0,40-0,44$ & 0,42 & $0,39-0,45$ & 0,981 & 0,42 & $0,40-0,44$ \\
\hline 18 & $\begin{array}{l}\text { Sintomas, sinais e achados } \\
\text { anormais de exames clínicos } \\
\text { e de laboratório não classifi- } \\
\text { cados em outra parte }\end{array}$ & 0,07 & $0,06-0,08$ & 0,16 & $0,14-0,18$ & $<0,001$ & 0,10 & $0,09-0,11$ \\
\hline 19 & $\begin{array}{l}\text { Lesões, envenenamento e } \\
\text { algumas outras consequên- } \\
\text { cias de causas externas }\end{array}$ & 0,02 & $<0,02-0,02$ & 0,02 & $0,02-0,03$ & 0,739 & 0,02 & $<0,02-0,02$ \\
\hline 20 & $\begin{array}{l}\text { Causas externas de } \\
\text { morbidade e de mortalidade }\end{array}$ & $<0,01$ & - & $<0,01$ & - & 0,012 & $<0,01$ & - \\
\hline 21 & $\begin{array}{l}\text { Fatores que influenciam o } \\
\text { estado de saúde e o contato } \\
\text { com os serviços de saúde }\end{array}$ & 1,97 & $1,93-2,02$ & 4,32 & $4,24-4,41$ & $<0,001$ & 2,83 & $2,79-2,87$ \\
\hline & Total (\%) & 100,00 & - & 100,00 & - & - & 100,00 & - \\
\hline & Total (n. absolutos) & 388.471 & - & 222.948 & - & - & 611.419 & - \\
\hline
\end{tabular}

Fonte: Base Nacional de Usuários de Medicamentos de Dispensação Excepcional no SUS (UFMG). 
TABELA 4

Distribuição dos usuários do Programa de Medicamentos de Dispensação Excepcional, por sexo, segundo principais diagnósticos registrados no início do tratamento

Brasil - 2000-2004

\begin{tabular}{|c|c|c|c|c|c|c|c|}
\hline \multirow{2}{*}{ Diagnósticos (CID-10) } & \multicolumn{2}{|c|}{ Mulheres } & \multicolumn{2}{|c|}{ Homens } & \multirow{2}{*}{ Valor $\mathbf{p}$} & \multicolumn{2}{|c|}{ Total } \\
\hline & $\%$ & IC 95\% & $\%$ & IC 95\% & & $\%$ & IC $95 \%$ \\
\hline Doença renal em estádio final & 6,63 & $6,55-6,71$ & 13,75 & $13,61-13,89$ & $<0,001$ & 9,22 & $9,15-9,30$ \\
\hline Esquizofrenia paranoide & 4,40 & $4,33-4,46$ & 10,22 & $10,10-10,35$ & $<0,001$ & 6,52 & $6,46-6,58$ \\
\hline $\begin{array}{l}\text { Osteoporose pós-menopáusica } \\
\text { com fratura patológica }\end{array}$ & 9,72 & $9,62-9,81$ & 0,05 & $0,04-0,06$ & $<0,001$ & 6,19 & $6,13-6,25$ \\
\hline Hipercolesterolemia pura & 4,42 & $4,35-4,48$ & 4,21 & $4,13-4,30$ & $<0,001$ & 4,34 & $4,29-4,39$ \\
\hline Hepatite viral crônica C & 2,38 & $2,33-2,43$ & 7,37 & $7,27-7,48$ & $<0,001$ & 4,20 & $4,15-4,25$ \\
\hline $\begin{array}{l}\text { Insuficiência renal crônica não } \\
\text { especificada }\end{array}$ & 2,87 & $2,82-2,92$ & 6,06 & $5,96-6,16$ & $<0,001$ & 4,03 & $3,98-4,08$ \\
\hline Osteoporose pós-menopáusica & 5,08 & $5,01-5,15$ & 0,01 & - & $<0,001$ & 3,23 & $3,19-3,27$ \\
\hline $\begin{array}{l}\text { Osteoporose em outras doen- } \\
\text { ças classificadas em outra parte }\end{array}$ & 4,51 & $4,45-4,58$ & 0,32 & $0,30-0,34$ & $<0,001$ & 2,98 & $2,94-3,03$ \\
\hline Outras hiperfunções da hipófise & 3,97 & $3,91-4,04$ & 0,95 & $0,91-0,99$ & $<0,001$ & 2,87 & $2,83-2,91$ \\
\hline Rim transplantado & 1,55 & $1,51-1,59$ & 3,16 & $3,08-3,23$ & $<0,001$ & 2,14 & $2,10-2,17$ \\
\hline Acne vulgar & 1,29 & $1,25-1,32$ & 3,37 & $3,29-3,44$ & $<0,001$ & 2,04 & $2,01-2,08$ \\
\hline Doença de Parkinson & 1,44 & $1,40-1,47$ & 2,77 & $2,70-2,84$ & $<0,001$ & 1,92 & $1,89-1,96$ \\
\hline Endometriose do útero & 2,90 & $2,85-2,96$ & 0,00 & - & $<0,001$ & 1,84 & $1,81-1,88$ \\
\hline $\begin{array}{l}\text { Doença de Alzheimer de início } \\
\text { precoce }\end{array}$ & 1,78 & $1,74-1,82$ & 1,75 & $1,70-1,81$ & 0,449 & 1,77 & $1,74-1,80$ \\
\hline Hipopituitarismo & 1,06 & $1,02-1,09$ & 2,49 & $2,43-2,56$ & $<0,001$ & 1,58 & $1,55-1,61$ \\
\hline Outros diagnósticos & 46,02 & $45,86-46,18$ & 43,52 & $43,31-43,72$ & $<0,001$ & 45,11 & $\begin{array}{r}44,98- \\
45,23\end{array}$ \\
\hline Total (\%) & 100,00 & - & 100,00 & - & - & 100,00 & - \\
\hline Total (n. absolutos) & 388.471 & - & 222.948 & - & - & 611.419 & - \\
\hline
\end{tabular}

Fonte: Base Nacional de Usuários de Medicamentos de Dispensação Excepcional no SUS (UFMG).

TABELA 5

Distribuição dos usuários do Programa de Medicamentos de Dispensação Excepcional, por sexo, segundo principais medicamentos utilizados no início do tratamento

Brasil - 2000-2004

\begin{tabular}{|c|c|c|c|c|c|c|c|}
\hline \multirow{2}{*}{ Medicamentos } & \multicolumn{2}{|c|}{ Mulheres } & \multicolumn{2}{|c|}{ Homens } & \multirow{2}{*}{ Valor $\mathbf{p}$} & \multicolumn{2}{|c|}{ Total } \\
\hline & $\%$ & IC 95\% & $\%$ & IC 95\% & & $\%$ & IC $95 \%$ \\
\hline $\begin{array}{l}\text { Eritropoetina Humana } \\
\text { Recombinante }\end{array}$ & 8,32 & $8,23-8,40$ & 18,03 & $17,87-18,19$ & $<0,001$ & 11,86 & $11,78-11,94$ \\
\hline Alendronato & 16,45 & $16,34-16,57$ & 1,21 & 1,16-1,26 & $<0,001$ & 10,89 & $10,82-10,97$ \\
\hline Calcitriol & 6,45 & $6,37-6,52$ & 6,84 & $6,74-6,95$ & $<0,001$ & 6,59 & $6,53-6,55$ \\
\hline $\begin{array}{l}\text { Calcitonina Sintética de } \\
\text { Salmão }\end{array}$ & 7,02 & $6,94-7,10$ & 0,62 & $0,59-0,65$ & $<0,001$ & 4,69 & $4,63-4,74$ \\
\hline Olanzapina & 3,04 & $2,99-3,10$ & 6,83 & $6,73-6,94$ & $<0,001$ & 4,42 & $4,37-4,48$ \\
\hline Risperidona & 2,85 & $2,80-2,90$ & 6,56 & $6,46-6,66$ & $<0,001$ & 4,20 & $4,16-4,25$ \\
\hline Goserelina & 5,35 & $5,28-5,42$ & 0,10 & $0,09-0,12$ & $<0,001$ & 3,43 & $3,39-3,48$ \\
\hline Azatioprina & 3,47 & $3,42-3,53$ & 2,38 & $2,32-2,44$ & $<0,001$ & 3,07 & $3,03-3,12$ \\
\hline Ciclosporina & 2,03 & $1,99-2,08$ & 4,79 & $4,70-4,88$ & $<0,001$ & 3,04 & $2,99-3,08$ \\
\hline $\begin{array}{l}\text { Goserelina+ Triptorelina } \\
\text { + Leuprolide }\end{array}$ & 4,26 & $4,20-4,32$ & 0,52 & $0,49-0,55$ & $<0,001$ & 2,90 & $2,85-2,94$ \\
\hline Interferon Alfa $2 \mathrm{a}$ ou $2 \mathrm{~b}$ & 1,57 & $1,53-1,61$ & 5,12 & $5,03-5,21$ & $<0,001$ & 2,86 & $2,82-2,91$ \\
\hline Isotretinoína & 1,74 & $1,69-1,78$ & 4,71 & $4,62-4,80$ & $<0,001$ & 2,82 & $2,78-2,86$ \\
\hline Acitretina & 1,34 & $1,31-1,38$ & 3,38 & $3,31-3,46$ & $<0,001$ & 2,08 & $2,04-2,12$ \\
\hline Rivastigmina & 2,00 & $1,96-2,05$ & 2,00 & $1,94-2,06$ & 0,832 & 2,00 & $1,97-2,04$ \\
\hline Sinvastatina & 1,93 & $1,89-1,97$ & 1,82 & $1,76-1,87$ & 0,002 & 1,89 & $1,86-1,92$ \\
\hline Outros medicamentos & 32,18 & $32,03-32,33$ & 35,10 & $34,91-35,30$ & $<0,001$ & 33,25 & $33,13-33,36$ \\
\hline Total (\%) & 100,00 & - & 100,00 & - & - & 100,00 & - \\
\hline Total (n. absolutos) & 388.471 & - & 222.948 & - & - & 611.419 & - \\
\hline
\end{tabular}

Fonte: Base Nacional de Usuários de Medicamentos de Dispensação Excepcional no SUS (UFMG). 
Pelo relacionamento dos registros da Base Nacional de Usuários de Medicamentos de Dispensação Excepcional com os do SIM, detectaram-se 40.941 óbitos no período. Na comparação entre sexos, os homens tiveram maiores proporções de óbitos $(9,82 \%)$ do que as mulheres $(4,90 \%)$ $(p<0,001)$.

Observa-se participação mais elevada de óbitos $(44,85 \%$ - IC 95\% 44,37-45,36) entre os indivíduos que tiveram o primeiro registro de Apac no programa em 2000, com equilíbrio na distribuição nos três anos subsequentes (6.809 em 2001, 6.935 em 2002 e 6.635 em 2003). Menor número de óbitos (2.200) ocorreu em pacientes que iniciaram o tratamento em 2004, em virtude do tempo de acompanhamento que foi até novembro do referido ano. Para os homens, observou-se maior proporção de óbitos em 2000 (46,26\%, contra $43,23 \%)$ e, para as mulheres, em $2001(17,65 \%$ vs. $15,75 \%)$ e $2002(17,59 \%$ vs. $16,37 \%)(p \leq 0,001)$.

Considerando-se os diagnósticos no início do tratamento, agrupados em capítulos da CID-10, daqueles indivíduos que evoluíram para óbito, 53,09\% entraram no programa com diagnóstico de doenças do aparelho geniturinário $(53,09 \%)$, seguidos por doenças do sistema osteomuscular e tecido conjuntivo $(9,90 \%)$ e doenças do aparelho circulatório (7,96\%). Estratificando-se pelo sexo, observaram-se maiores proporções de óbitos para os homens com diagnóstico de doenças infecciosas e parasitárias $(3,42 \%$, contra $1,68 \%$ para as mulheres), neoplasias $(2,12 \%$ vs. $1,65 \%)$, doenças endócrinas $(6,35 \%$ vs. $5,78 \%)$, doenças do aparelho circulatório $(9,06 \%$ vs. $6,70 \%)$, doenças da pele $(1,17 \%$ vs. $0,70 \%)$ e doenças do aparelho geniturinário $(56,90 \%$ vs. $48,71 \%)(p<0,05)$. Já entre as mulheres, a maior participação ocorreu para doenças do sistema osteomuscular e do tecido conjuntivo (18,39\% vs. $2,52 \%$, $\mathrm{p}<0,001$ ) (Tabela 6).

Considerando-se ainda o diagnóstico específico, no início do tratamento, daqueles indivíduos que evoluíram para óbito, $29 \%$ entraram no programa com diagnóstico de doença renal em estádio final, sendo que os quatro diagnósticos mais prevalentes $(57,46 \%)$ estavam relacionados às doenças renais. Osteoporose figurou entre os diagnósticos iniciais mais frequentes entre os que faleceram. Observaram-se diferenças entre sexo, com maior participação de homens para doença renal em estádio final (31,34\%, contra $26,31 \%$ para as mulheres), insuficiência renal crônica (13,17\% vs. 11,68\%), doença renal hipertensiva $(6,19 \%$ vs. $4,40 \%$ ), outra insuficiência renal crônica $(3,19 \%$ vs. $2,61 \%)$, rim transplantado (2,94\% vs. $2,08 \%)$, síndrome nefrítica crônica $(2,07 \%$ vs. $1,70 \%)$, hepatite viral crônica C $(2,26 \%$ vs. $1,13 \%)$, hipertensão arterial $(1,64 \%$ vs. $1,20 \%)$ e doença de Parkinson $(1,25 \%$ vs. $0,99 \%)(p<0,05)$. As mulheres apresentaram maiores proporções em doença de Alzheimer (1,72\%, contra 1,36\% para os homens) e osteoporose em outras doenças classificadas em outras partes $(2,80 \%$ vs. $0,35 \%)(p<0,01)$. Erros de digitação ou outros problemas ocorreram no registro de osteoporose pós-menopáusica com fraturas, com relatos de ocorrência em indivíduos do sexo masculino (Tabela 7 ).

Analisando-se a causa básica de morte, observa-se que os problemas renais estão relacionados às três principais causas de mortes. Entre as 1.529 causas de morte identificadas, 17 diagnósticos concentraram $50,63 \%$ de todos os óbitos. Estratificando-se pelo sexo, as causas de morte que apresentaram maiores proporções, entre os homens, foram insuficiência renal crônica não especificada $(12,10 \%$, contra $10,54 \%$ para as mulheres), doença renal hipertensiva $(6,84 \%$ vs. $5,89 \%)$, infarto agudo do miocárdio $(4,45 \%$ vs. $3,86 \%)$, hemorragia intracerebral $(1,75 \%$ vs. 1,41$)$, insuficiência renal não especificada $(1,33 \%$ vs. $1,04 \%)$ e neoplasia dos brônquios $(0,96 \%$ vs. $0,73 \%)(p<0,01)$, enquanto, para as mulheres, corresponderam a causas relacionadas a mortes sem assistência $(2,16 \%$, contra $1,61 \%$ para os homens), diabetes mellitus sem complicações $(1,32 \%$ vs. $0,74 \%)$ e outras doenças cerebrovasculares $(1,12 \%$ vs. $0,76 \%)(p<0,001)$ (Tabela 8) 
TABELA 6

Distribuição dos óbitos de usuários do Programa de Medicamentos de Dispensação Excepcional, por sexo, segundo capítulos da CID referentes aos diagnósticos no início do tratamento Brasil - 2000-2004

\begin{tabular}{|c|c|c|c|c|c|c|c|c|}
\hline & \multirow{2}{*}{ Capítulos CID-10 } & \multicolumn{2}{|c|}{ Mulheres } & \multicolumn{2}{|c|}{ Homens } & \multirow{2}{*}{ Valor $p$} & \multicolumn{2}{|c|}{ Total } \\
\hline & & $\%$ & IC $95 \%$ & $\%$ & IC 95\% & & $\%$ & IC $95 \%$ \\
\hline 1 & $\begin{array}{l}\text { Algumas doenças infecciosas e } \\
\text { parasitárias }\end{array}$ & 1,68 & $1,51-1,88$ & 3,42 & \multicolumn{2}{|c|}{$3,18-3,67<0,001$} & 2,61 & $2,46-2,77$ \\
\hline 2 & Neoplasias & 1,65 & $1,47-1,84$ & 2,12 & \multicolumn{2}{|c|}{$1,94-2,32<0,001$} & 1,90 & $1,77-2,04$ \\
\hline 3 & $\begin{array}{l}\text { Doenças do sangue e dos ór- } \\
\text { gãos hematopoiéticos e alguns } \\
\text { transtornos imunitários }\end{array}$ & 2,04 & $1,84-2,25$ & 2,13 & $1,94-2,33$ & 0,53 & 2,09 & $1,95-2,23$ \\
\hline 4 & $\begin{array}{l}\text { Doenças endócrinas, nutricio- } \\
\text { nais e metabólicas }\end{array}$ & 5,78 & $5,45-6,12$ & 6,35 & $6,03-6,68$ & 0,017 & 6,08 & $5,85-6,32$ \\
\hline 5 & $\begin{array}{l}\text { Transtornos mentais e compor- } \\
\text { tamentais }\end{array}$ & 3,49 & $3,23-3,76$ & 3,72 & $3,47-3,98$ & 0,206 & 3,61 & $3,43-3,80$ \\
\hline 6 & Doenças do sistema nervoso & 5,40 & $5,08-5,73$ & 5,51 & $5,21-5,82$ & 0,642 & 5,46 & $5,24-5,68$ \\
\hline 7 & Doenças do olho e anexos & 0,02 & $0,01-0,05$ & 0,02 & $0,01-0,05$ & 0,900 & 0,02 & $0,01-0,04$ \\
\hline 9 & $\begin{array}{l}\text { Doenças do aparelho } \\
\text { circulatório }\end{array}$ & 6,70 & $6,35-7,07$ & 9,06 & \multicolumn{2}{|c|}{$8,68-9,45<0,001$} & 7,96 & $7,70-8,23$ \\
\hline 10 & $\begin{array}{l}\text { Doenças do aparelho } \\
\text { respiratório }\end{array}$ & 0,45 & $0,36-0,56$ & 0,53 & $0,44-0,64$ & 0,258 & 0,49 & $0,43-0,57$ \\
\hline 11 & Doenças do aparelho digestivo & 1,07 & $0,93-1,23$ & 1,33 & $1,18-1,49$ & 0,332 & 1,21 & $1,11-1,32$ \\
\hline 12 & $\begin{array}{l}\text { Doenças da pele e do tecido } \\
\text { subcutâneo }\end{array}$ & 0,70 & $0,59-0,84$ & 1,17 & \multicolumn{2}{|c|}{$1,04-1,33<0,001$} & 0,96 & $0,86-1,06$ \\
\hline 13 & $\begin{array}{l}\text { Doenças do sistema } \\
\text { osteomuscular e do tecido } \\
\text { conjuntivo }\end{array}$ & 18,39 & $17,84-18,95$ & 2,52 & \multicolumn{2}{|c|}{$2,32-2,74<0,001$} & 9,90 & $9,62-10,20$ \\
\hline 14 & $\begin{array}{l}\text { Doenças do aparelho } \\
\text { geniturinário }\end{array}$ & 48,71 & $48,00-49,42$ & 56,90 & \multicolumn{2}{|c|}{$56,24-57,56<0,001$} & 53,09 & $52,60-53,57$ \\
\hline 15 & Gravidez, parto e puerpério & 0,06 & $0,03-0,11$ & 0,00 & \multicolumn{2}{|c|}{$-<0,001$} & 0,03 & $0,01-0,05$ \\
\hline 17 & $\begin{array}{l}\text { Malformações congênitas, } \\
\text { deformidades e anomalias } \\
\text { cromossômicas }\end{array}$ & 0,65 & $0,54-, 078$ & 0,70 & $0,59-0,82$ & 0,553 & 0,68 & $0,60-0,72$ \\
\hline 18 & $\begin{array}{l}\text { Sintomas, sinais e achados } \\
\text { anormais de exames clínicos e } \\
\text { de laboratório não classificados } \\
\text { em outra parte }\end{array}$ & 0,09 & $0,05-0,15$ & 0,15 & $0,10-0,21$ & 0,096 & 0,12 & $0,09-0,06$ \\
\hline 19 & $\begin{array}{l}\text { Lesões, envenenamento e } \\
\text { algumas outras conseqüências } \\
\text { de causas externas }\end{array}$ & 0,05 & $0,02-0,10$ & 0,04 & $0,02-0,08$ & 0,594 & 0,05 & $0,03-0,07$ \\
\hline 20 & $\begin{array}{l}\text { Causas externas de morbidade } \\
\text { e de mortalidade }\end{array}$ & 0,00 & - & 0,01 & - & 0,187 & 0,00 & - \\
\hline 21 & $\begin{array}{l}\text { Fatores que influenciam o esta- } \\
\text { do de saúde e o contato com os } \\
\text { serviços de saúde }\end{array}$ & 3,07 & $2,83-3,32$ & 4,34 & $4,07-4,62$ & $<0,001$ & 3,74 & $3,56-3,93$ \\
\hline Tot & al (\%) & 100,00 & - & 100,00 & - & - & 100,00 & - \\
\hline Tot & al (n. absolutos) & 190.053 & - & 21.888 & - & - & 40.941 & - \\
\hline
\end{tabular}

Fonte: Base Nacional de Usuários de Medicamentos de Dispensação Excepcional no SUS (UFMG). 
TABELA 7

Distribuição dos óbitos de usuários do Programa de Medicamentos de Dispensação Excepcional, por sexo, segundo principais diagnósticos no início do tratamento Brasil - 2000-2004

\begin{tabular}{|c|c|c|c|c|c|c|c|}
\hline \multirow{2}{*}{ Diagnóstico (CID-10) } & \multicolumn{2}{|c|}{ Mulheres } & \multicolumn{2}{|c|}{ Homens } & \multirow{2}{*}{ Valor $\mathbf{p}$} & \multicolumn{2}{|c|}{ Total } \\
\hline & $\%$ & IC $95 \%$ & $\%$ & IC $95 \%$ & & $\%$ & IC $95 \%$ \\
\hline $\begin{array}{l}\text { Doença renal em } \\
\text { estádio final }\end{array}$ & 26,31 & $25,68-26,93$ & 31,34 & $30,73-31,96$ & $<0,001$ & 29,00 & $28,56-29,44$ \\
\hline $\begin{array}{l}\text { Insuficiência renal crôni- } \\
\text { ca não especificada }\end{array}$ & 11,68 & $11,22-12,14$ & 13,17 & $12,72-13,62$ & $<0,001$ & 12,47 & $12,16-12,80$ \\
\hline $\begin{array}{l}\text { Doença renal } \\
\text { hipertensiva com } \\
\text { insuficiência renal }\end{array}$ & 4,40 & $4,11-4,70$ & 6,19 & $5,88-6,52$ & $<0,001$ & 5,36 & $5,14-5,81$ \\
\hline $\begin{array}{l}\text { Outra insuficiência renal } \\
\text { crônica }\end{array}$ & 2,61 & $2,38-2,84$ & 3,19 & $5,88-6,52$ & $<0,001$ & 2,92 & $2,76-3,09$ \\
\hline $\begin{array}{l}\text { Osteoporose } \\
\text { pós-menopáusica com } \\
\text { fratura patológica }\end{array}$ & 6,11 & $5,77-6,46$ & 0,03 & $0,01-0,07$ & $<0,001$ & 2,86 & $2,70-3,03$ \\
\hline Rim transplantado & 2,08 & $1,88-2,29$ & 2,94 & $2,72-3.18$ & $<0,001$ & 2,54 & $2,39-2,70$ \\
\hline $\begin{array}{l}\text { Transtornos } \\
\text { glomerulares no } \\
\text { diabetes mellitus }\end{array}$ & 2,14 & $1,94-2,35$ & 2,36 & $2,17-2,57$ & 0,134 & 2,26 & $2,12-2,41$ \\
\hline Esquizofrenia paranoide & 1,97 & $1,78-2,18$ & 2,12 & $1,94-2,33$ & 0,283 & 2,05 & $1,92-2,20$ \\
\hline $\begin{array}{l}\text { Síndrome nefrítica crôni- } \\
\text { ca - não especificada }\end{array}$ & 1,70 & $1,52-1,89$ & 2,07 & $1,88-2.26$ & 0,007 & 1,90 & $1,77-2,03$ \\
\hline Hepatite viral crônica C & 1,13 & $0,99-1,29$ & 2,26 & $2,07-2,46$ & $<0,001$ & 1,73 & $1,61-1,86$ \\
\hline $\begin{array}{l}\text { Doença de Alzheimer de } \\
\text { início precoce }\end{array}$ & 1,72 & $1,53-1,91$ & 1,36 & $1,21-1,53$ & 0,003 & 1,53 & $1,41-1,65$ \\
\hline $\begin{array}{l}\text { Osteoporose em outras } \\
\text { doenças classificadas em } \\
\text { outra parte }\end{array}$ & 2,80 & $2,57-3,04$ & 0,35 & $0,28-0,44$ & $<0,001$ & 1,49 & $1,38-1,62$ \\
\hline $\begin{array}{l}\text { Hipertensão essencial } \\
\text { (primária) }\end{array}$ & 1,20 & $1,05-1,36$ & 1,64 & $1,47-1,81$ & $<0,001$ & 1,43 & $1,32-1,55$ \\
\hline Doença de Parkinson & 0,99 & $0,85-1,14$ & 1,25 & $1,11-1,41$ & 0,015 & 1,13 & $1,03-2,24$ \\
\hline $\begin{array}{l}\text { Diabetes mellitus não-in- } \\
\text { sulino-dependente - com } \\
\text { complicações renais }\end{array}$ & 1,00 & $0,86-1,15$ & 1,02 & $0,90-1,17$ & 0,833 & 1,01 & $0,92-1,12$ \\
\hline Outros diagnósticos & 33,16 & $32,49-33,83$ & 29,73 & $29,12-30,34$ & $<0,001$ & 31,33 & $30,88-31,79$ \\
\hline Total (\%) & 100,00 & - & 100,00 & - & - & 100,00 & ( \\
\hline Total (n. absolutos) & 19.053 & - & 21.888 & - & - & 40.941 & \\
\hline
\end{tabular}

Fonte: Base Nacional de Usuários de Medicamentos de Dispensação Excepcional no SUS (UFMG).

TABELA 8

Distribuição dos óbitos de usuários do Programa de Medicamentos de Dispensação Excepcional, por sexo, segundo causas básicas de morte

Brasil - 2000-2004

\begin{tabular}{|c|c|c|c|c|c|c|c|}
\hline \multirow{2}{*}{ Causas de morte (CID-10) } & \multicolumn{2}{|c|}{ Mulheres } & \multicolumn{2}{|c|}{ Homens } & \multirow{2}{*}{ Valor $p$} & \multicolumn{2}{|c|}{ Total } \\
\hline & $\%$ & IC $95 \%$ & $\%$ & IC $95 \%$ & & $\%$ & IC 95\% \\
\hline $\begin{array}{l}\text { Insuficiência renal crônica não } \\
\text { especificada }\end{array}$ & 10,54 & $10,11-10,99$ & 12,10 & $11,67-12,54$ & $<0,001$ & 11,37 & $11,07-11,69$ \\
\hline $\begin{array}{l}\text { Diabetes mellitus não } \\
\text { especificado - com } \\
\text { complicações renais }\end{array}$ & 9,91 & $9,50-10,35$ & 9,67 & $9,28-10,07$ & 0,401 & 9,78 & $9,50-10,08$ \\
\hline $\begin{array}{l}\text { Doença renal hipertensiva } \\
\text { com insuficiência renal }\end{array}$ & 5,89 & $5,57-6,24$ & 6,84 & $6,51-7,19$ & $<0,001$ & 6,40 & $6,17-6,64$ \\
\hline
\end{tabular}

(continua) 
(continuação)

\begin{tabular}{|c|c|c|c|c|c|c|c|}
\hline \multirow{2}{*}{ Causas de morte (CID-10) } & \multicolumn{2}{|c|}{ Mulheres } & \multicolumn{2}{|c|}{ Homens } & \multirow{2}{*}{ Valor $p$} & \multicolumn{2}{|c|}{ Total } \\
\hline & $\%$ & IC $95 \%$ & $\%$ & IC 95\% & & $\%$ & IC $95 \%$ \\
\hline $\begin{array}{l}\text { Infarto agudo do miocárdio } \\
\text { não especificado }\end{array}$ & 3,86 & $3,59-4,14$ & 4,45 & $4,19-4,74$ & 0,003 & 4,18 & $3,99-4,38$ \\
\hline $\begin{array}{l}\text { Acidente vascular cerebral, } \\
\text { não especificado como } \\
\text { hemorrágico ou isquêmico }\end{array}$ & 2,42 & $2,21-2,66$ & 2,10 & $1,92-2,30$ & 0,280 & 2,25 & $2,11-2,40$ \\
\hline Morte sem assistência & 2,16 & $1,96-2,38$ & 1,61 & $1,45-1,79$ & $<0,001$ & 1,87 & $1,74-2,01$ \\
\hline Pneumonia não especificada & 1,93 & $1,74-2,13$ & 1,81 & $1,64-2,00$ & 0,382 & 1,86 & $1,74-2,00$ \\
\hline Septicemia não especificada & 1,83 & $1,64-2,03$ & 1,64 & $1,47-1,81$ & 0,139 & 1,72 & $1,60-1,86$ \\
\hline $\begin{array}{l}\text { Outras causas mal definidas } \\
\text { e as não especificadas de } \\
\text { mortalidade }\end{array}$ & 1,60 & $1,42-1,78$ & 1,64 & $1,48-1,82$ & 0,694 & 1,62 & $1,50-1,75$ \\
\hline $\begin{array}{l}\text { Hemorragia intracerebral } \\
\text { não especificada }\end{array}$ & 1,41 & $1,25-1,59$ & 1,75 & $1,58-1,93$ & 0,006 & 1,59 & $1,47-1,72$ \\
\hline $\begin{array}{l}\text { Broncopneumonia não } \\
\text { especificada }\end{array}$ & 1,38 & $1,22-1,55$ & 1,48 & $1,33-1,66$ & 0,352 & 1,43 & $1,32-1,55$ \\
\hline $\begin{array}{l}\text { Doença pulmonar obstrutiva } \\
\text { crônica não especificada }\end{array}$ & 1,30 & $1,15-1,48$ & 1,26 & $1,12-1,42$ & 0,684 & 1,28 & $1,17-1,39$ \\
\hline Neoplasia maligna da próstata & 0,05 & $0,02-0,09$ & 2,34 & $2,15-2,56$ & $<0,001$ & 1,28 & $1,17-1,39$ \\
\hline $\begin{array}{l}\text { Insuficiência renal não } \\
\text { especificada }\end{array}$ & 1,04 & $0,90-1,20$ & 1,33 & $1,19-1,50$ & 0,006 & 1,20 & $1,09-1,31$ \\
\hline $\begin{array}{l}\text { Diabetes mellitus não } \\
\text { especificado sem complicações }\end{array}$ & 1,32 & $1,16-1,49$ & 0,74 & $0,64-0,87$ & $<0,001$ & 1,01 & $0,92-1,14$ \\
\hline $\begin{array}{l}\text { Outras doenças } \\
\text { cerebrovasculares } \\
\text { especificadas }\end{array}$ & 1,12 & $0,98-1,29$ & 0,76 & $0,65-0,88$ & $<0,001$ & 0,93 & $0,74-1,03$ \\
\hline $\begin{array}{l}\text { Neoplasia maligna dos brônquios } \\
\text { ou pulmões, não especificada }\end{array}$ & 0,73 & $0,62-0,86$ & 0,96 & $0,84-1,10$ & 0,012 & 0,85 & $0,77-0,95$ \\
\hline Outros diagnósticos & 51,51 & $50,80-52,23$ & 47,50 & $46,83-48,16$ & $<0,001$ & 49,37 & $48,88-49,85$ \\
\hline Total (\%) & 100,00 & - & 100,00 & - & - & 100,00 & - \\
\hline Total (n. absolutos) & 190.053 & - & 21.888 & - & - & 40.941 & - \\
\hline
\end{tabular}

Fonte: Base Nacional de Usuários de Medicamentos de Dispensação Excepcional no SUS (UFMG).

Nota: Resultados obtidos a partir do pareamento das bases de dados SIM e Apac.

\section{Discussão}

Poucos estudos no Brasil avaliaram o Programa de Medicamentos de Dispensação Excepcional, principalmente enfocando o indivíduo, uma vez que os dados da Apac são registros contábeis relativos a procedimentos de alto custo, neste caso o medicamento. Assim, podem existir diversas Apacs para um mesmo paciente e o sistema de informação não está estruturado de maneira a produzir informações centradas no indivíduo.

A coorte formada a partir do pareamento das bases de dados selecionadas permitiu identificar e descrever as características de
611.419 indivíduos, sendo a maioria do sexo feminino, com predominância de adultos e idosos mais jovens (30-69 anos). Os homens apresentaram-se um pouco mais jovens do que as mulheres. Estas características acompanham o perfil da transição demográfica brasileira, resultado das mudanças nos padrões demográfico e epidemiológico que ocorreram no Brasil, ao longo do século XX: maior expectativa de vida ao nascer e maior percentual de mulheres. As perdas para o sexo masculino entre adultos e jovens são causadas, principalmente, pela violência; e o grande declínio dos óbitos por causas maternas acentuam os aspectos positivos da transição para as mulheres e os diferenciais 
entre os sexos (CARVALHO, 1997-1998; VERMELHO et al., 2001).

Os resultados encontrados são coerentes com os observados em estudos conduzidos no Brasil e em sociedades industrializadas que apontam que, embora vivam mais do que os homens, as mulheres relatam mais morbidade e problemas psicológicos e, portanto, utilizam mais os serviços de saúde (MACINTYRE et al., 1996 e 1999; BIRD; RIECKER, 1999). Idades avançadas e sexo feminino são as características mais consistentemente associadas à maior utilização de serviços de saúde (CAPILHEIRA; SANTOS, 2006; TRAVASSOS et al., 2002; MENDOZA; BERIA, 2001; LIMA-COSTA; LOYOLA FILHO, 2008; PINHEIRO et al., 2002; LOUVISON et al., 2008).

O aumento da idade está relacionado ao crescimento da incidência e prevalência das doenças crônicas. Em relação às diferenças entre sexos, o maior uso de serviços pelas mulheres seria influenciado por aspectos que se relacionam ao fato de as mulheres perceberem suas necessidades de saúde de maneira diferente, apresentando mais queixas e doenças crônicas do que os homens, embora, geralmente, com menor gravidade. Além disso, frequentemente, consideram-se os fatores genéticos e hormonais para explicar a maior utilização dos serviços e consequentemente, maior medicalização (LIMA-COSTA; LOYOLA FILHO, 2008; VERBRUGGE, 1989).

O perfil demográfico é diferenciado entre as regiões. Quase metade dos indivíduos atendidos pelo programa residia no Sudeste do país e a menor proporção encontravase no Centro-Oeste. Considerando-se as taxas de pacientes atendidos para cada 100 habitantes, os valores mais elevados correspondiam aos residentes nas Regiões Norte (2000-2002) e Sudeste (2003 e 2004) e os menores foram encontrados entre os moradores no Sul (2000-2002) e Nordeste (2004).

Historicamente, o acesso aos serviços de saúde esteve ligado à disponibilidade, sendo que os habitantes das regiões mais desenvolvidas apresentavam maiores taxas de utilização de serviços do que os residentes naquelas menos desenvolvidas. Neste sentido, é surpreendente o resultado obser- vado nos três primeiros anos de seguimento deste estudo, que mostrou a maior taxa de pacientes atendidos/100 habitantes entre os residentes na Região Norte e a menor entre aqueles do Sul.

No Brasil, pesquisa com dados de 1989, portanto anterior à implantação do SUS, revelou uma situação de marcadas desigualdades sociais no acesso aos serviços de saúde no país (TRAVASSOS et al., 2006). Já em 1996/1997, com base em dados da PNAD, observa-se um movimento de tímida redução dos níveis de desigualdades em relação a 1989, ainda que persista uma longa distância para atingir uma dinâmica francamente promissora de alcance de maiores graus de equidade (TRAVASSOS et al., 2000).

Em 2003, os residentes no Sudeste e Sul tiveram maior acesso do que os habitantes das outras regiões, mas detectou-se melhoria do acesso aos serviços de saúde entre todas as regiões, com exceção do Norte, que não foi estudada (TRAVASSOS et al., 2006). Por outro lado, indicadores do Programa de Saúde da Família apontam maiores proporções de pessoas atendidas no Nordeste $(63,2 \%)$ e Centro-Oeste (43,9\%) em comparação à Região Sudeste (33,2\%) (BRASIL, 2007b). As taxas de pacientes atendidos segundo região de residência, observadas no presente estudo para 2003 e 2004, mostram coerência com esses resultados.

Essas alterações nos padrões de acesso podem estar refletindo as recentes mudanças na forma de financiamento que, ao levar em conta dados epidemiológicos e demográficos, promove uma diminuição das iniquidades regionais. Essa tendência também pode estar ocorrendo no programa avaliado, uma vez que o número de pacientes cadastrados vem aumentando substancialmente (BRASIL, 2007a), mas são necessárias mais investigações para melhor compreensão da cobertura alcançada.

Vários determinantes da utilização dos serviços de saúde têm sido descritos e podem contribuir para o entendimento das diferenças encontradas entre regiões, como aqueles fatores relacionados: à necessidade de saúde - morbidade, gravidade e urgência 
da doença; aos usuários - características demográficas (idade e sexo), socioeconômicas (renda, educação), culturais (religião) e psíquicas; aos prestadores de serviços tempo de graduação, especialidade, características psíquicas, experiência profissional, tipo de prática; e à organização - recursos disponíveis, características da oferta (disponibilidade de médicos, hospitais, ambulatórios), modo de remuneração, acesso geográfico e social (PINEAULT; DAVELUY, 1996 apud TRAVASSOS; MARTINS, 2004).

Para Travassos e Martins (2004), a utilização dos serviços de saúde representa o centro do funcionamento dos sistemas de saúde, sendo considerada uma medida de acesso. Em média, 122.284 pessoas, por ano, utilizaram o Programa de Medicamentos de Dispensação Excepcionais no período de 2000-2004. Observou-se na coorte que grande proporção de pacientes foi atendida em 2000 , o que pode ser devido ao recente processo de informatização do sistema Apac/SIA, ocasionando uma sobre-estimação do número de indivíduos atendidos naquele ano. Aumento crescente de utilização do programa de medicamentos excepcionais foi observado entre 2001 e 2004. A maior utilização destes serviços também pode estar relacionada à melhoria do gerenciamento, à maior disseminação do programa, ao incremento de tecnologias e às políticas públicas relacionadas aos medicamentos de alto custo.

Com o envelhecimento da população brasileira e o aumento da longevidade da população, as doenças crônicas passaram a representar uma expressiva e crescente demanda aos serviços de saúde, evidenciando a necessidade de conhecer melhor a sua prevalência. As informações disponíveis nesta análise são inadequadas para o estudo da prevalência de doenças que requerem medicamentos de alto custo, por suas diversas limitações, tais como demanda não-atendida e/ou atendimentos efetuados na rede privada. Entretanto, os dados fornecem uma noção das prioridades em saúde. Os diagnósticos mais prevalentes no início do tratamento estão agrupados no capítulo das doenças do aparelho geniturinário (135.444), seguido das doenças do sistema osteomuscular (132.608), das quais se destacam as doenças renais e osteoporoses, respectivamente.

A doença renal crônica constitui hoje um importante problema de saúde pública. O número de pacientes tratados para doença renal em estágio final tem demonstrado crescimento contínuo desde o estabelecimento de diálise como uma terapia de manutenção da vida e os avanços no transplante de órgãos (MOELLER et al., 2002). Estimativas do Censo Brasileiro de Diálise (CBD) relataram que, em 2002, eram 54.523 pacientes em diálise no Brasil, sendo que a incidência cresce cerca de $8 \%$ ao ano (ROMÃO, 2004). Dos pacientes, a maioria utiliza medicamentos para o tratamento de anemia renal crônica, condição dos doentes renais crônicos, sendo que o SUS é o provedor majoritário da eritropoetina humana recombinante. Salienta-se a importância da disponibilização desta medicação para pacientes com doenças renais, uma vez que a ausência de tratamento está associada à hipertrofia ventricular esquerda, eventos cardiovasculares, aumento de hospitalização e redução da qualidade de vida, particularmente quando o paciente apresenta baixos níveis de hemoglobina (MOIST et al., 2008).

Para a osteoporose, embora seja a doença osteometabólica mais comum, pouco se conhece sobre sua prevalência no Brasil. Reconhece-se a importância do tratamento e da prevenção da osteoporose por meio do Programa, que disponibiliza diversos medicamentos para o tratamento, como alendronato de sódio, calcitriol, alfacalcidol, calcitonina, raloxifeno. Atualmente, ainda são disponibilizados teriparatida, pamidronato e risendronato (PROTOCOLOS CLÍNICOS E DIRETRIZES TERAPÊUTICAS, 2008). O uso da medicação previne ou reduz a incidência de fraturas vertebrais e não-vertebrais, especialmente em mulheres em idades avançadas, que são as mais acometidas pela doença (BOCK et al., 2008). Osteoporose também pode ocorrer com alta frequência em pacientes com doenças renais, devido ao acometimento renal, visto que o rim é responsável por vários processos fisiológicos relacionados aos ossos. 
O perfil de morbidade é diferenciado entre homens e mulheres, o que, por sua vez, reflete em distintos padrões de utilização de medicamentos. Nessa coorte, os diagnósticos no início do tratamento mais frequentemente registrados entre os homens foram: doenças renais, esquizofrenia paranoide, hepatite viral crônica C, acne, doença de Parkinson e hipopituitarismo. Estas diferenças também foram observadas na literatura, sendo que, dos pacientes em diálise, $57 \%$ eram do sexo masculino e, para os portadores de hepatite C, $61,0 \%$ eram homens (FERREIRA; SILVEIRA, 2004; SESSO et al., 2008).

No que se refere à esquizofrenia e ao hipopituitarismo, observa-se que mulheres e homens são igualmente afetados (REGAL et al., 2001; RADLER; NABER, 2007). Todavia, na esquizofrenia, a doença inicia-se mais cedo em homens do que em mulheres e esses tendem a ter sintomas mais graves e negativos, sendo mais prejudicados na sua capacidade de socialização (RADLER, NABER, 2007; GROSSMAN et al., 2008). Homens também são geralmente tratados com doses mais elevadas de antipsicóticos (RADLER; NABER, 2007), o que pode explicar as diferenças encontradas na coorte estudada.

Para a acne, a prevalência é reconhecidamente maior entre os homens, devido à influência androgênica (COSTA et al., 2008). A doença de Parkinson pode ocorrer em pessoas de ambos os sexos, apesar de alguns estudos epidemiológicos demonstrarem uma maior frequência no sexo masculino (WOOTEN et al., 2004). No presente estudo, hipercolesterolemia foi mais comum entre mulheres, observação que também está de acordo com a literatura (SPOSITO, 2007).

Entre os óbitos detectados no programa, a proporção foi maior em homens $(9,8 \%)$ do que em mulheres $(4,9 \%)$. Já está bem estabelecido na literatura que os homens apresentam maiores taxas de mortalidade do que as mulheres. Este fenômeno pode ser explicado por diversos fatores, envolvendo aspectos biológicos, sociais, psicológicos e interpretações. É ainda provável que seja devido a múltiplas causas, que incluem diferenças biológicas entre os sexos, como fatores genéticos e hormonais, além de respostas do sistema imunológico. Diferenças comportamentais também estão incluídas, como a exposição a diversos riscos e a relutância em procurar e cumprir com o tratamento médico. Outra consideração importante é que parte da diferença observada pode ser devida a desafios metodológicos, tais como a não-participação, a seletiva subnotificação de problemas de saúde e o início de tratamento retardado por parte dos homens (OKSUZYAN et al., 2008).

Maior proporção de óbitos ocorreu entre indivíduos que entraram no Programa em 2000 e a menor entre os que ingressaram em 2004. Observou-se uma proporção semelhante para aqueles que entraram nos anos intermediários. Quase metade dos óbitos detectados ocorreu em pessoas com diagnóstico de doença renal no início do tratamento, sendo que as causas básicas de morte mais frequentes estavam relacionadas às doenças renais.

No Brasil, em 2005, as doenças renais representaram a oitava causa de internação em idosos. A insuficiência renal foi a 16 a causa de morte na faixa etária de 80 anos ou mais, a $20^{\underline{a}}$ na de 70 a 79 anos e a $22^{\underline{a}}$ na de 60 a 69 anos (Datasus), evidenciando sua relevância como causa de morte que aumenta proporcionalmente à idade.

Por último, cabe observar que o sistema Apac/SUS tem como propósito registrar a produção, a cobrança e o pagamento de medicamentos de dispensação excepcional. Portanto, esse sistema apresenta limitações de caráter estrutural, como as lacunas de informação quanto a características importantes para análise, por exemplo, aquelas relacionadas a renda ou condições clínicas. Além disso, existem os erros de alimentação das bases de dados, as dificuldades na codificação dos procedimentos e a finalidade de faturamento (CHERCHIGLIA et al., 2007). Pelo exposto, mesmo com a realização do pareamento determinístico-probabilístico que permitiu a construção de uma coorte dos pacientes atendidos em um período de cinco anos, o estudo traz as limitações de utilizar uma base de dados cuja finalidade original é administrativa. 


\section{Conclusões}

$\mathrm{O}$ alto custo dos medicamentos tem sido identificado como uma importante barreira ao acesso e utilização destes produtos, fato que evidencia a relevância de programas como o de Medicamentos de Dispensação Excepcional, garantindo sua disponibilização, por meio dos serviços públicos de saúde. Os medicamentos são insumos essenciais ao cuidado, que contribuem para incrementar a qualidade de vida da população, sendo, muitas vezes, condição para manutenção da vida. Por isso, a eficácia do gerenciamento do Programa e a organização da atenção à saúde nos serviços representam, hoje, preocupação de todos os gestores do setor, seja pela natureza das práticas de assistência neles desenvolvidas, seja pela totalidade dos recursos por eles absorvidos.

A promoção do acesso aos medicamentos de dispensação excepcional tem como requisitos a instituição do critério epidemiológico de seleção dos medicamentos, a elaboração e revisão periódica dos protocolos clínicos, a racionalidade do seu uso, a estruturação de rede de atenção

\section{Referências}

BIRD, C. E.; RIEKER, P. P. Gender matters: an integrated model for understanding men's and women's. Social Science and Medicine, n.4, p.745-755, 1999.

BOCK, O.; FELSENBERG, D. Bisphosphonates in the management of postmenopausal osteoporosis-optimizing efficacy in clinical practice. Clin Interv Aging, n. 3(2), p.27997, 2008.

BRASIL. Lei n. 8.080 (Lei Orgânica da Saúde), de 19 de setembro de 1990. Dispõe sobre as condições para a promoção, proteção e recuperação da saúde, a organização dos serviços correspondentes, e dá outras providências. Diário Oficial da União, 20 set. 1990.

BRASIL. Portaria GM MS n. 373, de 27 de fevereiro de 2002. Aprova, na forma do Anexo desta Portaria, a Norma Operacional à saúde e a divulgação de informações referentes ao Programa (BRASIL, 2007a).

Dados administrativos, como os registros da Apac, apresentam grande potencialidade de informação e são úteis para traçar a trajetória do usuário nos serviços de saúde. O pareamento probabilísticodeterminístico possibilitou a identificação dos indivíduos e a construção de uma coorte histórica obtida a partir da (re)construção da trajetória dos pacientes que utilizaram medicamentos de dispensação excepcional, permitindo um maior conhecimento do perfil epidemiológico e demográfico desses pacientes. Mais do que isso, o banco de dados desenvolvido propicia uma série de análises específicas por doenças, que podem contribuir para avaliações de efetividade e eficiência dos protocolos clínicos. Essas informações fornecem subsídios aos tomadores de decisão no que tange ao planejamento das ações e à oferta de medicamentos de alto custo pelo SUS, colaborando para o aperfeiçoamento das políticas públicas no Brasil e melhoria da qualidade da atenção prestada aos pacientes.

da Assistência à Saúde NOAS-SUS 01/2002. Diário Oficial da União, 28 fev. 2002.

BRASIL. Portaria GM n. 2.577 de 27 de outubro de 2006. Aprova o Componente de Medicamentos de Dispensação Excepcional. Diário Oficial da União, 30 out. 2006.

BRASIL. Conselho Nacional de Secretários de Saúde. Assistência Farmacêutica no SUS. Brasília: Conass, 2007a

BRASIL. Comissão Nacional sobre Determinantes Sociais da Saúde. As causas sociais das iniqüidades em saúde no Brasil. DATASUS/MS, julho 2007b. Disponível em: <http://www.cndss.fiocruz.br/pdf/home/relatorio.pdf > . Acesso em: $01 \mathrm{dez} .2008$.

CAPILHEIRA, M. F.; SANTOS, I. S. Fatores individuais associados à utilização de consultas médicas por adultos. Rev. Saúde Pública, v. 40, n. 3, p. 436-443, 2006. 
CARVALHO, J. A. M. de. Demographic dynamics in Brazil recent trends and perspectives. Brazilian Journal of Population Studies, Brasília, v. 1, p 5-23, 1997/98.

CHERCHIGLIA, M. L. et al. A construção da base de dados nacional em Terapia Renal Substitutiva (TRS) centrada no indivíduo: aplicação do método de linkage determinístico-probabilístico. Revista Brasileira de Estudos de População, v. 24(1), p.163-167, 2007.

COSTA, A.; ALCHORNE, M. M. A.; GOLDSCHMIDT, M. C. B. Fatores etiopatogênicos da acne vulgar. An. Bras. Dermatol., Rio de Janeiro, v. 83, n. 5, out. 2008.

FERREIRA, C. T.; SILVEIRA, T. R. Hepatites virais: aspectos da epidemiologia e da prevenção. Rev. Bras. Epidemiol., v.7, n.4, p. 473-487, 2004.

GROSSMAN, L. S.; HARROW, M.; ROSEN, C.; FAULL, R.; STRAUSS, G.P. Sex differences in schizophrenia and other psychotic disorders: a 20-year longitudinal study of psychosis and recovery. Compr. Psychiatry, v. 49, n. 6, p. 523-529, 2008.

LIMA-COSTA, M. F.; LOYOLA FILHO, A. I. Fatores associados ao uso e à satisfação com os serviços de saúde entre usuários do Sistema Único de Saúde na região metropolitana de Belo Horizonte, Estado de Minas Gerais, Brasil. Epidemiol. Ser. Saúde, v. 17(4), p. 247-257, 2008.

LOUVISON, M. C. P. et al. Desigualdades no uso e acesso aos serviços de saúde entre idosos do município de São Paulo. Rev. Saúde Pública [on-line], v. 42, n. 4, p. 733-740.

MACINTYRE, S.; HUNT, K.; SWEETING, H. Gender differences in health: are things really as simple as they seem? Social Science and Medicine, v. 42(4), p. 617-624, 1996.

MACINTYRE, S. F. G.; HUND, K. Do women "over-report" morbidity? Men's and women's responses to structured prompting on a standard question on long standing illness. Social Science and Medicine, n. 48, p. 89-98, 1999.
MENDOZA-SASSI, R.; LBERIA, J. U. Utilización de los servicios de salud: una revisión sistemática sobre los factores relacionados. Cad. Saúde Pública, v. 17, n. 4, p. 819-832, 2001.

MOELLER, S.; GIOBERGE, S.; BROWN, G. ESRD patients in 2001: global overview of patients, treatment modalities and development trends. Nephrol Dial Transplant, n. 17, p. 2071-2076, 2002.

MOIST, L. M. et al. Clinical practice guidelines for evidence-based use of erythropoieticstimulating agents. Kidney International, $n$. 74 (Suppl. 110), p. S12-S18, 2008.

OKSUZYAN, A.; JUEL, K.; VAUPEL, J. W.; CHRISTENSEN, K. Men: good health and high mortality. Sex differences in health and aging. Aging Clin. Exp. Res, v. 20, n.2, p. 91-102, 2008.

PINHEIRO, R. S.; VIACAVA, F.; TRAVASSOS, C.; BRITO, A. S. Gênero, morbidade, acesso e utilização de serviços de saúde no Brasil. Ciênc. Saúde Coletiva [on-line], v.7, n.4, p. 687-707, 2002.

PROTOCOLOS CLÍNICOS E DIRETRIZES TERAPÉUTICAS - Medicamentos Excepcionais. Disponível em: <http://www. opas.org.br/medicamentos/docs/pcdt/ do_o28_00.htm >. Acesso em: 12 nov. 2008.

QUEIROZ, O. V.; GUERRA JÚNIOR, A. A.; MACHADO, C.J.; ANDRADE, E. I. G.; MEIRA JÚNIOR, W.; ACURCIO, F. A.; SANTOS FILHO, W.; CHERCHIGLIA, M.L. A construção da Base Nacional de Dados em Terapia Renal Substitutiva (TRS) centrada no indivíduo: relacionamento dos registros de óbitos pelo subsistema de Autorização de Procedimentos de Alta Complexidade (Apac/ SIA/SUS) e pelo Sistema de Informações sobre Mortalidade (SIM) - Brasil, 2000-2004. Epidemiol. Serv. Saúde, Brasília, v. 18(2), p.193-196, abr.-jun. 2009.

RADLER, T. J.; NABER, D. Sex-specific differences in schizophrenia. MMW. Fortschr. Med, v. 149, n 24, p. 32-34, 2007.

REGAL, M.; PARAMO, C.; SIERRA, S. M.; GARCIA-MAYOR, R. V. Prevalence and incidence of hypopituitarism in an adult Caucasian population in northwestern Spain. 
Clin. Endocrinol.(Oxf), v. 55, n.6, p.735740, 2001.

ROMAO JÚNIOR, J. E. Doença renal crônica: definição, epidemiologia e classificação. J. Bras. Nefrol., n. 26 (Supl. 1), p.1-3, 2004.

SAWYER, D. O.; LEITE, I. C.; ALEXANDRINO, R. Perfis de utilização do serviços de saúde no Brasil. Ciência \& Saúde, Rio de Janeiro, n. 7 v.4, p. 757-776, 2002.

SESSO, R.; LOPES, A. A.; THOMÉ, F. S.; BEVILACQUA, J. L.; ROMÃO JUNIOR, J. E.; LUGON, J. Relatório do Censo Brasileiro de Diálise, 2008. J. Bras. Nefrol., n.30(4), p. 233-8, 2008.

SPOSITO, A. C. et al. IV Diretriz Brasileira sobre Dislipidemias e Prevenção da Aterosclerose: Departamento de Aterosclerose da Sociedade Brasileira de Cardiologia. Arq. Bras. Cardiol., São Paulo, 2009.

TRAVASSOS, C.; VIACAVA, F.; FERNADES, C.; ALMEIDA, C. M. Desigualdades geográficas e sociais na utilização de serviços de saúde no Brasil. Ciência e Saúde Coletiva, v.5, p.133-149, 2000.

TRAVASSOS, C.; MARTINS, M. Uma revisão sobre os conceitos de acesso e utilização de serviços de saúde. Cad. Saúde Pública, v.20, supl. 2, p. S190-S198, 2004.

TRAVASSOS, C.; VIACAVA, F.; PINHEIRO, R.; BRITO, A. Utilização dos serviços de saúde no Brasil: gênero, características familiares e condição social. Rev. Panam. Salud Pública, v. 11(5-6), p.365-73, 2002.

TRAVASSOS, C.; OLIVEIRA, E. X. G.; VIACAVA, F. Desigualdades geográficas e sociais no acesso aos serviços de saúde no Brasil: 1998 e 2003. Ciênc. Saúde Coletiva [on-line], vol.11, n.4, p. 975-986, 2006.

VERBRUGGE, L. M. The Twain meet: empirial explanations of sex differences in health and mortality. Journal of Health and Social Behaviour, n. 30, p.282-304, 1989.

VERMELHO, L. L. et al. Transição epidemiológica e indicadores de saúde atuais. Cadernos Saúde Coletiva, v. 2, n. 9, p.111-126, 2001

WOOTEN, G. F.; CURRIE, L. J.; BOVBJERG, V. E.; LEE, J. K., PATRIE, J. Are men at greater risk for Parkinson's disease than women? Journal of Neurology, Neurosurgery and Psychiatry with Practical Neurology, n. 75, p.637-639, 2004.

\section{Resumen}

Perfil demográfico y epidemiológico de los usuarios de medicamentos de costo elevado en el Sistema Único de Salud

El Programa de Medicamentos Excepcionales del Ministerio de Salud tiene como objetivo satisfacer la demanda de medicamentos de alto valor unitario, o de aquellos empleados en enfermedades crónicas que impliquen un tratamiento de costo elevado. Con el objetivo de describir el perfil demográfico y epidemiológico de los pacientes incluidos en el programa, se realizó una vinculación probabilística-determinística de datos provenientes de registros del DATASUS (Banco de Datos del Sistema Único de Salud): Autorizaciones de Procedimientos de Alta Complejidad/Alto Costo (Apac/SIA) y Sistema de Información sobre Mortalidad (SIM). La cohorte formada a partir de la vinculación de las bases de datos identificó a 611.419 individuos que comenzaron el tratamiento en el período 2000-2004. Los análisis se han separado por sexo, región de residencia, diagnóstico y medicamentos más utilizados. La construcción de esta cohorte histórica permitió la descripción de las características demográficas, epidemiológicas y de utilización de medicamentos de los usuarios del programa. Además, el banco de datos generado hace posible la realización de una serie de análisis específicos para determinación de enfermedades, que pueden contribuir a evaluaciones de eficacia y eficiencia de las alternativas terapéuticas incluidas en los protocolos clínicos, con el objetivo de proporcionar subsidios 
a quienes toman decisiones con respecto a la planificación de las acciones y la oferta de medicamentos de alto costo por parte del SUS.

Palabras clave: Utilización de medicamentos. Alto costo. Vinculación. SUS.

\section{Abstract \\ Epidemiological profile of high cost medicines users in the Brazilian Health System}

The Program for High-Cost Medicines of the Brazilian Health Ministry was set up to respond to the demand for high unit-cost medication or for medication used for chronic diseases that imply a high overall cost for treatment. To describe the epidemiological and demographic profiles of patients enrolled in the program, a probabilistic-deterministic connection was made between data in sections of the Health Ministry's databases (DATASUS), namely, the Outpatient Information System (APAC/SIA) and the Mortality Information System (SIM). The cohort formed by linking databases identified 611,419 individuals who began treatment between 2000 and 2004. The analyses were disaggregated by sex, region of residence, diagnoses and most widely used drugs. The construction of this historical cohort made possible a description of the epidemiological characteristics and drugs used by the program's users. The database generated can also provide analyses for specific diseases, with results that can contribute to evaluations of effectiveness and efficiency of clinical protocols, in order to better inform decision-makers regarding the planning and supplying of high-cost medication by the Brazilian Health Ministry.

Keywords: Medical Drug Use, High Cost Medications, databases, Brazilian Health Ministry.

Recebido para publicação em 23/06/2009. Aceito para publicação em 07/10/2009. 